\title{
Identification of teaching priorities for ultrasound-guided regional anesthesia as first-line pain management in a swiss university emergency department
}

\author{
Eckehart Schöll*, Dieter Kolleth, Gilbert Krähenbühl, Christian H. Nickel and Roland Bingisser
}

*Correspondence: eckehart.schoell@usb.ch

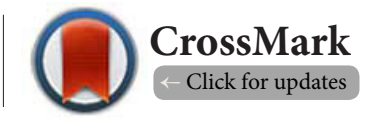

Department of Emergency Medicine, University Hospital Basel, Switzerland.

\begin{abstract}
Background: About half of the patients who visit our emergency Department (ED) complain of pain. Since early and consequent pain relief is of great importance, we started to introduce a first-line pain control by ultrasound-guided regional anesthesia. The aim of this study was to identify teaching priorities for ultrasoundguided regional anesthesia (USRA) in the ED.

Methods: We included ED-patients with pain of different causes. Exclusion criteria were refusal by the patient or the specialist physician, infection at the injection site, and allergies to local anesthetics (LA). Ultrasonographic guided LA was placed into the compliant epineural space of the targeted nerval structure. Only single-shot USRA was applied. Interventions were performed by two emergency physicians and one emergency fellow resident.

Results: We included 322 patients, median age 64.6 years (min. 18, max. 103). Pathologies: fractures 180 (55.9\%), soft tissue injuries 45(14\%), dislocated joints 44(13.7\%), infections $27(8.4 \%)$, arthralgia $12(3.7 \%)$, neuralgia of the trunk $7(2.2 \%)$, acute ischemia $6(1.9 \%)$, one complex regional pain syndrome (0.3\%). No complications were observed.

Conclusion: Main indications for USRA in our ED are fractures and soft tissue injuries of the extremities. Therefore, our future teaching priority will focus on USRA of interscalenic, supraclavicular/axillar plexus, and femoral as well as obturator nerve.

Keywords: Pain, emergency medicine, nerve block, ultrasound, regional anesthesia, brachial plexus block, axillary block, forearm block, sciatic block, femoral block
\end{abstract}

\section{Introduction}

Pain is a challenging problem in about half of all patients presenting to emergency departments (ED) [1]. Nevertheless, oligoanalgesia appears to be a global phenomenon in EDs, whereas overuse of opioids has been described as well. Therefore, a pain management protocol is required by the Swiss Society for Emergency and Rescue Medicine (SSERM) as one of the quality criteria of a certified ED.

Furthermore, early and sufficient pain controlin the ED is one of the important objectives, especially in patients with fractures, since those injuries regularly entail relevant numbers of transfers in the course of the work-up and transfer to the operating room (OR). Additionally, due to organizational reasons, there is a waiting period until interventions are performed. This waiting time, for example in femoral neck fractures, can last hours [2]. Within that period, analgesia is of utmost importance.

Moreover, the mean age of patients with fractures of the wrist or femoral neck is higher than 65 years and often they suffer from comorbidities. Sufficient analgesia represents an important and complex task in these persons, since inadequate pain management in older patients is known to be associated with delirium and other adverse health outcomes. Commonly the use of NSAID is contraindicated in these patients, leaving opioids as the first line pain medication. Nevertheless, this type of analgesia has a wide range of adverse effects. Another consideration is the fact, that many older patients are neither 
able to adequately express their suffering, nor to handle more complex systems like patient controlled analgesia. Since there is increasing concern about the potential risks caused by long-term opioid treatment, low-dose ketamine [3] and intravenous lidocaine infusions [4] are considered as alternatives in the management of acute pain in the ED.

Ultrasound-guided regional anesthesia (USRA) is a practical technique for first-line pain control [5]. With an appropriate needle and ultrasound equipment, a trained operator is able to reach almost every peripheral nerve. For most procedures there are no absolute contraindications except for allergies and non-consent. Moreover, besides to physical measures, regional anesthesia is the only analgesic procedure which does not have to be applied systemically.

The purpose of the current study is to observe potential indications for USRA in the ED by quantifying certain clinical situations. For that reason we reviewed prospectively logged cases of USRA performed at our ED. The ultimate goal is to identify teaching priorities for emergency physicians.

\section{Methods \\ Study design}

This is a prospective observational study in an urban Swiss ED of an academic center with $50^{\prime} 000$ visits per year to determine the feasibility of different ultrasound guided nerve blocks under emergency conditions. The responsible Ethics Committee on research involving humans approved the study protocol.

\section{Participants}

Inclusion criteria: Depending on the availability of a trained interventionist, we included adult patients ( $\geq 18 \mathrm{yrs}$.) with painful conditions of the upper or lower extremity, the trunk or the ear for different reasons: fractures, and/or dislocated joints, abscesses or infected wounds, soft tissue lesions, foreign body injuries, unbearable pain caused by algoneurodystrophy, or ischemia and arthralgia caused by other conditions. Included participants were waiting for surgery in the OR or were planned to get abscess incision or foreign body removal in the ED. Extended preoperative regional analgesia via catheter was not intended in these patients.

Exclusion criteria were refusal of the procedure by the patient or by the specialist physician performing an intervention, infection at the planned injection site, and known allergies to local anesthetics.

\section{Interventions}

The disinfection of the skin was achieved with Octenisept ${ }^{\oplus}$ (2-Phenoxyethanol, Octenidin, Octenidin dihydrochlorid). For the ultrasound guided interventions a HITACHI Hi Vision AVIUS with a $50 \mathrm{~mm}$ linear-array probe $(5.0-13.0 \mathrm{MHz})$ was used. Injections were performed with two different needles: PAJUNK SonoPlex Stim cannula 22 Gx50mm and PAJUNK SonoPlex Stim cannula $20 \mathrm{G} \times 150 \mathrm{~mm}$. Nevertheless, the control of the correct position of the needle tip was achieved only by visualization and without additional nerval stimulation. Under real-time ultrasonographic guidance, the needle was advanced until the tip reached the compliant epineural space of the target. We used the out-of-plane as well as the in-plane needle approach, depending on the site of injection (Table 1). Only single-shot regional anesthesia was applied. For the injection we used Bupivacaine 0.5\% (Sintetica SA) when the desired duration of analgesia was at least 12 hours, and

Table 1. Baseline demographics and technical details to ultrasound guided regional anaesthesia.

\begin{tabular}{|c|c|c|c|c|c|c|}
\hline Affected body region & Nerval structures & Needle & $\begin{array}{l}\text { Punction } \\
\text { technique }\end{array}$ & No. of blocks & $\begin{array}{l}\text { ml local anaesthetic } \\
\text { Mean } \pm \text { St.Dev }\end{array}$ & $\begin{array}{l}\text { Median age Yrs } \\
\text { (IQR) }\end{array}$ \\
\hline Forehead & Supraorbital nerve & Short & SAX/OOP & $1(0.3 \%)$ & $4 \pm 0$ & $33.6(33.6 ; 33.6)$ \\
\hline Ear & Great auricular nerve & Short & SAX/IP & $2(0.6 \%)$ & $3.5 \pm 0.5$ & $41.4(40.2 ; 42.7)$ \\
\hline Shoulder and upper arm & Interscalenic brachial plexus & Short & SAX/OOP & $77(23.9 \%)$ & $10.3 \pm 2.1$ & $65.3(53.6 ; 81.2)$ \\
\hline Shoulder - rotator cuff & Suprascapular nerve & Short & SAX/OOP & $20(6.2 \%)$ & $9.3 \pm 1.7$ & $48.3(37.4 ; 55.3)$ \\
\hline Ellbow and forearm & $\begin{array}{l}\text { Supraclavicular or } \\
\text { axillar plexus }\end{array}$ & Long/short & $\begin{array}{l}\text { SAX/IP or } \\
\text { OOP }\end{array}$ & $90(28 \%)$ & $20.5 \pm 3.9$ & $59.4(41.8 ; 75.7)$ \\
\hline Hand & $\begin{array}{l}\text { Ulnar, median, radial } \\
\mathrm{n} \text {. at the forearm }\end{array}$ & Short & SAX/OOP & $18(5.6 \%)$ & $10 \pm 2.1$ & $43.6(33.4 ; 50.9)$ \\
\hline Hip and knee & $\begin{array}{l}\text { Femoral nerve and obturator } \\
\text { nerve }\end{array}$ & Long/short & SAX/IP & $72(22.4 \%)$ & $22.1 \pm 5.2$ & $84.5(71.3 ; 88.8)$ \\
\hline Lateral thigh & Lat. fem. cut. nerve & Short & SAX/OOP & $1(0.3 \%)$ & $4 \pm 0$ & $74.4(74.4 ; 74.4)$ \\
\hline Ankle and foot & Sciatic nerve & Long & SAX/IP & $28(8.7 \%)$ & $22.6 \pm 4.9$ & $50.1(32.9 ; 68.5)$ \\
\hline Intercostal & Thoracal paravertebral & Long & LA/IP & $9(2.8 \%)$ & $9.1 \pm 0.6$ & $59.3(50.8 ; 64.6)$ \\
\hline Lumbal & $\begin{array}{l}\text { Transverse abdominis plane/ } \\
\text { Shamrock }\end{array}$ & Long & LA/IP & $4(1.2 \%)$ & $18.75 \pm 2.2$ & $39.7(26.6 ; 50.2)$ \\
\hline Sum & -- & -- & -- & 322 & -- & -- \\
\hline
\end{tabular}

LA: longitudinal axis of the nerve structure; SAX: Short axis of the nerve structure; IP: In plane-view of the needle; OOP: Out of plane-view of the needle 
Scholl et al. Emergency Medicine \& Health Care 2016,

Prilocaine 2\% (Sintetica SA) for brief interventions with no more than 3 hours duration.

\section{Training}

The first author is USRA-course instructor; the second attending physician and the emergency resident were participants in a two-day USRA workshop.

\section{Results}

Between January 2014 and December 2015 we included 322 adult patients (female 190, male 132) with a median age of 64.6 years, ranging from 18 to almost 103 years. 158 of the patients (49.1\%) were over 65 year old. Baseline demographics are shown in Table 1.

Most of the interventions (292) were performed by the first author, attending physician; additional interventions (16) were performed by a second attending physician, and by an emergency resident (14) under supervision.

Underlying pathologies: $180(55.9 \%)$ patients presenting with fractures were the largest group, followed by $45(14 \%)$ patients with soft tissue injuries undergoing wound care, where $7(2.2 \%)$ patients needed removal of foreign bodies. USRA was used for reduction in $44(13.7 \%)$ cases of dislocated joints and $27(8.4 \%)$ times for the surgical treatment of infected wounds or abscesses. In 12(3.7\%) cases we used the method for pain relief in arthralgia and $7(2.2 \%)$ times in neuralgia of the trunk and in $6(1.9 \%)$ cases of acute ischemia. We also used USRA successfully in one case $(0.3 \%)$ of complex regional pain syndrome. In the three latter conditions, the benefit of a few hours pain-relief was intended to bridge the time until the definitive treatment could be started.

A wide variety of puncture-sides were used (Table 1). Only once we performed the shamrock lumbar plexus block as described by Axel R. Sauter et al., [6] in a patient with an acetabular fracture as well as a supraorbital nerve block to treat an abscess at the forehead.

Complications, defined as intravascular injections, prolonged paresthesia and paralysis or infection of the injection site, were not seen neither was any rescue analgesia needed. As shown in Figure 1, there is a steady progress in the number of interventions performed per month, mainly by a growing acceptance of the method within the ED-team and specialists. No interventionist was available due to holiday absence in August 2014.

\section{Discussion}

Our investigation focused on the feasibility of USRA in the ED, and the distribution of feasible interventions. We found that $63.7 \%$ (205) of all USRA were applied for analgesia of the upper limbs, while $31.4 \%$ (101) were used for analgesia of the lower limbs. About half of our patients receiving USRA were aged 65 or older. These patients may have the most benefit from localized non-systemic analgesia. Blocks for femoral neck and trochanteric fractures were performed in the group with the oldest patients (median age 84.5 years). A cautious use of opiates while providing sufficient analgesia is of crucial importance for the prevention of hypoventilation and delirium in this group [1]. Overall, we mainly provided USRA in fractures followed by soft tissue injuries of the extremities. Most USRA were performed to block the interscalenic, supraclavicular, or axillar plexus, as well as femoral and obturator nerves. For that reason, our

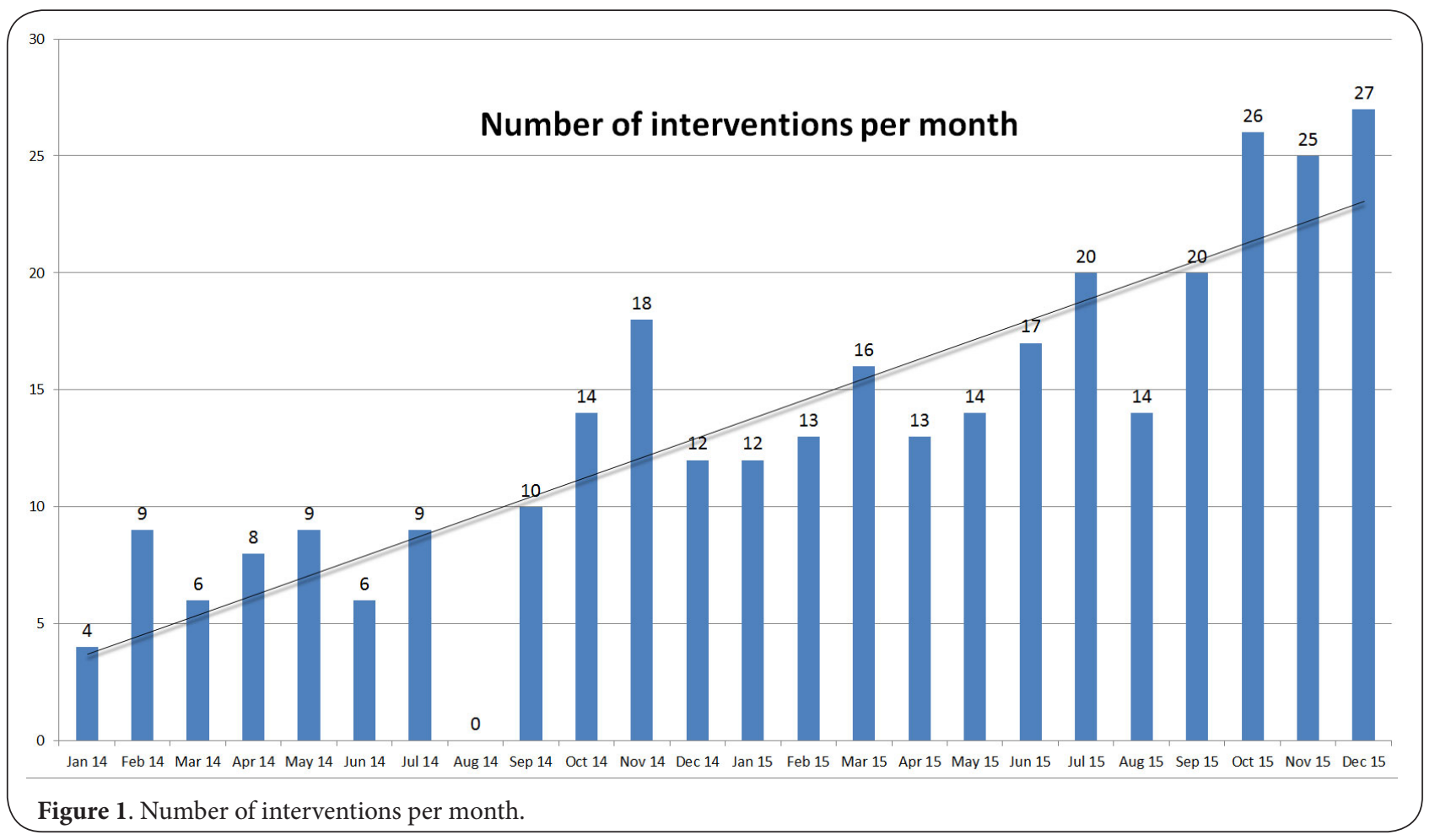


further teaching priorities for emergency physicians will focus on these procedures. The shamrock-technique seems to be too complex in the emergency setting.

Ten years ago, Liebmann et al., [7] published about a simple procedure of an ultrasound-guided regional anesthesia of the forearm executed by emergency physicians. Since this time, several investigations with different blocking techniques for the shoulder and hip region have shown that the method has great benefits as first-line analgesia in the emergency setting. In 2011 Blaivas et al., showed that patients with shoulder dislocation treated with interscalene blocks had a shorter length of stay in the ED [8]. Most studies on first-line regional anesthesia in the ED have been published in the field of femoral neck fractures. Here, ultrasound guided blocks [9], as well as the classic landmark-technique [10] have been studied. Results show that in patients, treated with first-line regional anesthesia in the ED, pain relief is timely and opiate demand lower. Additionally, the length of hospital stay and hospital mortality seems to be lower in these patients. Because regional anesthesia has been performed only by emergency physicians it could be shown that USRA in the ED is a practical procedure if these physicians have undergone appropriate training. Since most peripheral nerves may be visualized by ultrasound, and can be reached using an appropriate needle, there are only few sites of somatic pain which cannot be treated by the methods described. Especially in the ever growing population of elderly patients, USRA offers many advantages as compared with opioid analgesia.

This study contains many limitations. Mainly, the three providers were not permanently available. Therefore, a realistic overview of the USRA indications in our ED is not possible. USRA was provided, if the interventionist chose to do so during the study period. For that reason, our further intension will focus on a systematic USRA-teaching of all attending physicians in our ED.

\section{Conclusion}

Based on our findings, the intension of the three operators to perform USRA in our ED are fractures and soft tissue injuries of the upper extremity, the hip, and the femoral region. For this reason, our further teaching priority will focus on USRA of the interscalenic, supraclavicular, or axillar plexus, as well as the femoral and obturator nerves.

\section{Competing interests}

The authors declare that they have no competing interests.

\section{Authors' contributions}

\begin{tabular}{|l|c|c|c|c|c|}
\hline Authors' contributions & ES & DK & GK & CHN & RB \\
\hline Research concept and design & $\checkmark$ & -- & -- & $\checkmark$ & $\checkmark$ \\
\hline Collection and/or assembly of data & $\checkmark$ & $\checkmark$ & $\checkmark$ & -- & -- \\
\hline Data analysis and interpretation & $\checkmark$ & $\checkmark$ & $\checkmark$ & $\checkmark$ & $\checkmark$ \\
\hline Writing the article & $\checkmark$ & -- & -- & $\checkmark$ & $\checkmark$ \\
\hline Critical revision of the article & $\checkmark$ & -- & -- & $\checkmark$ & $\checkmark$ \\
\hline Final approval of article & $\checkmark$ & -- & -- & -- & $\checkmark$ \\
\hline
\end{tabular}

\section{Acknowledgement}

This work was supported by scientific funds of the University Hospital Basel.

Publication history

EIC: Joseph Varon, University of Texas, USA.

Received: 20-Jul-2016 Final Revised: 26-Aug-2016

Accepted: 05-Sep-2016 Published: 14-Sep-2016

\section{References}

1. Cantrill SV, Brown MD, Carlisle RJ, Delaney KA, Hays DP, Nelson LS, O'Connor RE, Papa A, Sporer KA, Todd KH and Whitson RR. Clinical policy: critical issues in the prescribing of opioids for adult patients in the emergency department. Ann Emerg Med. 2012; 60:499-525. | Article I PubMed

2. Westberg M, Snorrason F and Frihagen F. Preoperative waiting time increased the risk of periprosthetic infection in patients with femoral neck fracture. Acta Orthop. 2013; 84:124-9. | Article I PubMed Abstract I PubMed FullText

3. Ahern TL, Herring AA, Miller S and Frazee BW. Low-Dose Ketamine Infusion for Emergency Department Patients with Severe Pain. Pain Med. 2015; 16:1402-9. I Article I PubMed

4. Golzari SE, Soleimanpour H, Mahmoodpoor A, Safari S and Ala A. Lidocaine and pain management in the emergency department: a review article. Anesth Pain Med. 2014; 4:e15444. | Article | PubMed Abstract I PubMed FullText

5. Bhoi S, Chandra A and Galwankar S. Ultrasound-guided nerve blocks in the emergency department. J Emerg Trauma Shock. 2010; 3:82-8. | Article | PubMed Abstract | PubMed FullText

6. Sauter AR, Ullensvang K, Bendtsen TF and Boerglum J. The "Shamrock Method" - a new and promising technique for ultrasound guided lumbar plexus blocks. Br J Anaesth. 2013.

7. Liebmann O, Price D, Mills C, Gardner R, Wang R, Wilson S and Gray A. Feasibility of forearm ultrasonography-guided nerve blocks of the radial, ulnar, and median nerves for hand procedures in the emergency department. Ann Emerg Med. 2006; 48:558-62. I Article I PubMed

8. Blaivas M, Adhikari S and Lander L. A prospective comparison of procedural sedation and ultrasound-guided interscalene nerve block for shoulder reduction in the emergency department. Acad Emerg Med. 2011; 18:922-7. | Article | PubMed

9. Lee HK, Kang BS, Kim CS and Choi HJ. Ultrasound-guided regional anesthesia for the pain management of elderly patients with hip fractures in the emergency department. ClinExpEmerg Med. 2014; 1:4955. I Article

10. Lees D, Harrison WD, Ankers T, A'Court J, Marriott A, Shipsey D, Chaplin $A$ and Reed MR. Fascia iliaca compartment block for hip fractures: experience of integrating a new protocol across two hospital sites. Eur J Emerg Med. 2016; 23:12-8. | Article | PubMed

Citation:

Schöll E, Kolleth D, Krähenbühl G, Nickel CH and Bingisser R. Identification of teaching priorities for ultrasound-guided regional anesthesia as first-line pain management in a swiss university emergency department. Emerg Med Health Care. 2016; 4:2. http://dx.doi.org/10.7243/2052-6229-4-2 